\title{
The short-term survival following acute myocardial infarction: A prospective observational study
}

Mohammad Aryaie ${ }^{1}$, Fozieh Bakhsha ${ }^{2 *}$, Seyyed Yaghub Jafari ${ }^{2}$, Zahra Yousefi $^{2}$, Ali Reza Heidari $^{1}$, Zahra Esmaeili ${ }^{3}$, Sakineh Sobhani ${ }^{3}$, Shima Aghili ${ }^{3}$

1. Health Management and Social Development Research Center, Golestan University of Medical Sciences, Gorgan, Iran

2. Laboratory Sciences Research Center, Golestan University of Medical Sciences, Gorgan, Iran

3. Research Committee, Golestan University of Medical Science, Gorgan, Iran

*Corresponding author: Tel: +98 9111775765 Fax: +98 17321655

Address: Laboratory Sciences Research Center, Golestan University of Medical Science, Herkan blv begining of Road Shastkola, Gorgan, Iran

E-mail: bakhsha_fo@yahoo.com

Received; 2016/01/31 revised; 2016/04/29 accepted; 2016/07/15

\section{Abstract}

Introduction: To investigate 28 days survival rate following first acute myocardial infarction (AMI) associated with the presence of classical risk factors and treatment modalities in Gorgan, north of Iran.

Materials and methods: Our cohort including all patients hospitalized due to AMI from 2010 to 2013. Data were collected on demographic, prophylactic drugs and classical coronary risk factors. Data were analyzed using Kaplan-Meier and log rank tests. Cox proportional hazard model was built to estimate relative risk by taking into account other variables.

Results: Median age of subjects was 58 and 64 for men and women, respectively; moreover, the occurrence of diabetes was 52.5 and 24.5 for them. A poorer outcome was detected in survival rate for women in the final model. Excess death occurrence in Fars or non- Persian ethnicity, and those who were not prescribed statin was detected in the adjusted model.

Conclusion: A better survival rate for those who were prescribed statin suggest that it could be beneficial in treatment modality and non-Persian ethnicities needed to be considered as a group of at risk for earlier screening programs. In spite of some other studies a poorer outcome following AMI for women was found even after taking into account age and comorbidity.

Keywords: Acute myocardial infarction, Survival, Risk factor, Treatment

\section{Introduction}

Cardiovascular disease is the first leading cause of death, and its burgeoning growth is more likely to be found in low and mediocre income countries (1). In many developed countries, death rate from coronary heart disease has been steadily declining which has been attributed to factors such as decreasing in incidence, increasing the short term survival after hospitalization and also improvement in treatment. The development of national registries in some countries is beginning to reveal the nature of coronary heart disease.
Improving lifestyles (reducing calorie intake and increasing physical activity) in patients in the region will be essential, although cultural and environmental barriers will render this difficult. Appropriate prescribing of pharmacologic treatments is essential in the prevention and management of cardiovascular disease. In particular, recent controversies relating to the therapeutic profile of betablockers may have reduced their use. The current evidence base suggests that betablockers are as effective as other therapies 
in preventing cardiovascular disease and that concerns relating to their use in hypertension and cardiovascular disease have been overstated. (2-4).

Cardiovascular disease and its associated risk factor such as, hypertension, diabetes mellitus are placed among top ten diseases, according to a DALY index in Iranian communities (5), which can incurred a heavy burden on patients and society.

the prevalence of coronary heart disease is promoted in turn by a high prevalence of cardiovascular risk factors, particularly smoking, hypertension, dyslipidemia, diabetes, and sedentary lifestyles previous history of myocardial infarction (6), age and gender has introduced as a risk factor for coronary heart disease $(6,7)$. In addition to these factors, Griffiths and colleagues have stated among secondary prophylactic drugs, statin are related to survival rate and no significant association was found for those who had been prescribed thrombolytic (2). However, some studies have been shown the positive beneficial effect of thrombolytic therapy on acute myocardial infarction (AMI) (8, 9).

Despite a significant reduction in incidence of coronary disease in various countries $(3,10,11)$ and advances in the treatment methods and appliances (12-14), the case fatality rate resulting from acute myocardial infarction has remained high in both sexes Most but not all studies suggest that women are less likely to develop coronary heart disease than men but are more likely to die when they do. Many reasons have been advanced to explain this observation. Women tend to be older than men at the time of their myocardial infarction (15).

The aim of this study was to investigate 28 days survival rate following first acute myocardial infarction and the effect of classical coronary risk factors (e.g.; hypertension, diabetes, etc.) and receiving secondary prophylactic drugs, including ACE inhibitors, B blocker, statin, Aspirin and uptake of thrombolysis on acute myocardial infarction.

\section{Materials and methods}

This study was confirmed by the Ethics Committee of the Golestan University of Medical Science.The subjects of our cohort consisted of all patients were hospitalized, in all public, educational and private hospitals, owing to First AMI in Gorgan, north of Iran from 2010 to 2013. Data were collected on gender, age at diagnosis, the presence of acute myocardial risk factors (diabetes, hypertension, ischemic heart disease, smoking or being addicted, previous or family history of heart attack, AMI characteristics including inferior or anterior stroke, treatment including ACE, Beta blocker, Thrombolytic, Aspirin and statin. All subjects were contacted by phone, and information on their current status and patients medical recording were also collected by trained interviewers. Information was collected from close relatives in cases who had passed away. Follow-up period was taken considered 28 days after emerging the first medical symptoms of myocardial infarction, including symptoms, electrocardiogram and abnormal enzyme $(16,17)$. No data were collected on those who could not be followed (e.g., those who had left their place). Death due to accident, Chronic obstructive pulmonary disease, cancer, Liver and kidney diseases, Cardiovascular diseases except for coronary, without any kind of coronary disease or Atherosclerosis at the first attack during 28 days or lost to follow-up, were considered as censor.

Kaplan-Meier and log rank tests were used to compare median survival rate. Cox proportional hazard models were built to estimate the patient's survival rate. The proportional hazard assumption was verified by $\log$ minus $\log$ approach. $\mathrm{P}$ value less than 0.05 was considered as significant. 


\section{Results}

We analyzed 413 Patients from AMI in our cohort. The mean age at diagnosis was $58.4 \pm 12.7$ and $63.7 \pm 11.2$, respectively, with a male to female ratio of 1.96 . Overall 48 deaths were identified among these cases, 17 of which were men and 31 of which were women. 20 (4.8\%) Deaths were identified due to other disease. The average follow-up time was $26.89 \pm 0.35$ days. The occurrence of diabetes was 24.5 and 52.5 for men and women, respectively (Table 1).

Table 1. Demographic and clinical feature of acute myocardial infarction subjects.

\begin{tabular}{|c|c|c|c|c|}
\hline Variables & & Male & Female & Both sexes \\
\hline \multicolumn{5}{|l|}{ Demographic } \\
\hline \multirow{2}{*}{ Residency } & Urban & $200(73.5)$ & $94(68.6)$ & 294(61.9) \\
\hline & Rural & $72(26.5)$ & $43(31.4)$ & $115(38.1)$ \\
\hline \multirow{3}{*}{ Ethnicity } & Fars or Persian & $163(90.1)$ & $77(83.7)$ & 240 (87.9) \\
\hline & Turkmen & 7 (3.9) & $9(9.8)$ & $16(5.9)$ \\
\hline & Sistani & $11(6.1)$ & $6(6.5)$ & $17(6.2)$ \\
\hline \multicolumn{5}{|l|}{ Medical history } \\
\hline \multirow{2}{*}{ Diabetic } & Yes & $67(24.5)$ & $73(52.5)$ & $140(33.9)$ \\
\hline & No & $207(75.5)$ & $66(47.5)$ & $273(66.1)$ \\
\hline \multirow{2}{*}{ Hypertension } & Yes & $99(36.1)$ & $77(55.4)$ & $176(42.6)$ \\
\hline & No & $175(63.9)$ & $62(44.6)$ & 237 (57.4) \\
\hline \multirow{2}{*}{ IHD } & Yes & $54(19.7)$ & $25(18)$ & $79(19.1)$ \\
\hline & No & $220(80.3)$ & $114(82)$ & $334(80.9)$ \\
\hline \multirow{2}{*}{ Previous history } & Yes & $48(26.2)$ & $20(25)$ & $68(25.9)$ \\
\hline & No & $135(73.8)$ & $60(75)$ & $195(74.1)$ \\
\hline \multirow{2}{*}{ Family history } & Yes & $63(34.6)$ & $21(25.3)$ & $84(31.7)$ \\
\hline & No & $119(65.4)$ & $62(74.7)$ & $181(68.3)$ \\
\hline \multirow{2}{*}{ Smoking } & Yes & $120(51.3)$ & $77(75.5)$ & 197 (58.6) \\
\hline & No & $114(48.7)$ & $25(24.5)$ & 139 (41.4) \\
\hline \multirow{2}{*}{ Addicted } & Yes & $105(43.4)$ & $27(26)$ & $132(38.2)$ \\
\hline & No & $137(56.6)$ & $77(74)$ & $214(61.8)$ \\
\hline Characteristic & Inferior & $114(54.8)$ & $42(44.7)$ & $156(51.7)$ \\
\hline Stroke & Anterior & $94(45.2)$ & $52(55.3)$ & $146(48.3)$ \\
\hline \multicolumn{5}{|l|}{ Treatment } \\
\hline \multirow{2}{*}{$\mathrm{ACE}$} & Yes & $118(43.2)$ & 55 (39.6) & $173(42)$ \\
\hline & No & $155(56.8)$ & $84(60.4)$ & $239(58)$ \\
\hline \multirow{2}{*}{ Beta blocker } & Yes & $164(60.1)$ & $92(66.2)$ & $256(62.1)$ \\
\hline & No & 109 (39.9) & $47(33.8)$ & 156 (37.9) \\
\hline \multirow{2}{*}{ Thrombolysis } & Yes & $197(72.2)$ & $82(59.4)$ & 279 (67.9) \\
\hline & No & $76(27.8)$ & $56(40.6)$ & $132(32.1)$ \\
\hline \multirow{2}{*}{ Asprine } & Yes & $246(90.1)$ & $121(87.1)$ & 367 (89.1) \\
\hline & No & $27(9.9)$ & $18(12.9)$ & $45(10.9)$ \\
\hline \multirow{2}{*}{ Statin } & Yes & $227(83.2)$ & $113(81.3)$ & $340(82.5)$ \\
\hline & No & $46(16.8)$ & $26(28.7)$ & $72(17.5)$ \\
\hline \multirow{3}{*}{ Status } & Death & $17(6.2)$ & $31(22.3)$ & $48(11.6)$ \\
\hline & Alive & $241(88)$ & $104(74.8)$ & $345(83.5)$ \\
\hline & Other & $16(5.8)$ & $4(2.9)$ & $20(4.8)$ \\
\hline
\end{tabular}

Data are shown as number (percent).

Univariate analysis indicated a higher significant survival rate for cases receiving treatment, including ACE inhibitor, Beta blocker and Aspirin. No significant association was found in survival rate for thrmbolysis. There was no difference observed in survival rate of diabetes, ischemic heart disease, smoking or addicted patients. The survival rate in patients with hypertension was significantly lower than in those who had not (Table 2). 
Table 2. Classical coronary risk factors, secondary prophylactic drugs and receiving thrombolysis on acute myocardial survival, unadjusted Cox regression model for time to death.

\begin{tabular}{|c|c|c|c|}
\hline \multicolumn{2}{|l|}{ Demographic Variables } & \multirow{2}{*}{$\begin{array}{c}\text { Number of deaths } \\
-\end{array}$} & \multirow{2}{*}{$\begin{array}{c}\text { Unadjusted HR } \\
1.06(1.04-1.09)^{* *}\end{array}$} \\
\hline Age & Continuous & & \\
\hline \multirow{2}{*}{ Gender } & Male & 17 & 1 \\
\hline & Female & 31 & $3.72(2.05-6.72)^{* * *}$ \\
\hline \multirow{2}{*}{ Residency } & Urban & 28 & 1 \\
\hline & Rural & 19 & $1.78(0.99-3.18)$ \\
\hline \multirow[b]{2}{*}{ Ethnicity } & Fars or Persian & 18 & 1 \\
\hline & $\begin{array}{l}\text { Non-Persian } \\
\text { (Sistani/Turkmen) }\end{array}$ & 6 & $2.59(1.03-6.53)^{*}$ \\
\hline \multicolumn{4}{|l|}{ Medical history } \\
\hline \multirow{2}{*}{ Diabetic } & Yes & 22 & $1.69(0.96-2.98)$ \\
\hline & No & 26 & 1 \\
\hline \multirow{2}{*}{ Hypertension } & Yes & 27 & $1.78(1.007-3.15)^{*}$ \\
\hline & No & 21 & 1 \\
\hline \multirow{2}{*}{ IHD } & Yes & 13 & $1.61(0.85-3.05)$ \\
\hline & No & 35 & 1 \\
\hline \multirow{2}{*}{ Smoking or addicted } & Yes & 13 & $1.27(0.41-3.88)$ \\
\hline & No & 4 & 1 \\
\hline \multicolumn{4}{|l|}{ Treatment } \\
\hline \multirow[t]{2}{*}{$\mathrm{ACE}$} & Yes & 11 & 1 \\
\hline & No & 36 & $2.52(1.28-4.94)^{*}$ \\
\hline \multirow{2}{*}{ Beta blocker } & Yes & 22 & 1 \\
\hline & No & 25 & $1.89(1.07-3.36)^{*}$ \\
\hline \multirow{2}{*}{ Thrombolysis } & Yes & 27 & 1 \\
\hline & No & 20 & $1.65(0.93-2.94)$ \\
\hline \multirow{2}{*}{ Aspirin } & Yes & 36 & 1 \\
\hline & No & 11 & $2.66(1.35-5.22)^{* *}$ \\
\hline \multirow{2}{*}{ Statin } & Yes & 31 & 1 \\
\hline & No & 16 & $2.61(1.43-4.78)^{*}$ \\
\hline
\end{tabular}

After adjusting for potential confounders including age at diagnosis, gender, ethnicity, treatment (ACE inhibitor, Beta blocker, Aspirin), and hypertension, patients who did not receive statin were 3.07 (95\% CI=1. 33-7.13) times more likely to die compared to those receiving statin (Table 3). The multiple cox regression models detected that mortality rate No serious violations of proportional hazard assumptions were observed after checking the model.

Table 3. Factors associated with survival in adjusted Cox regression model for time to death.

\begin{tabular}{llcc}
\hline Variables & Category & Adjusted HR & Confidence interval \\
\hline Age & Continuous & 1.08 & $1.03-1.13 * * *$ \\
Gender & Male & 3.77 & $1.54-9.22 * *$ \\
& Female & & $1.03-6.87 *$ \\
Ethnicity & Fars or Persian & 2.66 & $1.33-7.13 * *$ \\
Statin & Non- Persian (Sistani or Turkmen) & 3.07 &
\end{tabular}

\section{Discussion}

We found that receiving statins was the most important independent predictor significantly associated with survival among acute myocardial infarction patients. Ethnicity, age and gender also significantly related to survival by taking into consideration others potential confounders.

Our finding showed a better survival for women than men. Gottlieb and colleague 
showed that older age and comorbidity are associated to lower survival in women, and no relationship was reported between therapeutic modalities, invasive coronary procedures and sex difference mortality (18). The higher mortality rate in women during 28 days after AMI has been shown in some other studies $(19,20)$.

Moreover, the excess mortality rate in men on arrival lead to have been estimated higher survival for them following hospitalization than women $(5,21,22)$. So, the gender differences might be derived from a selection bias. According to this, long term survival can be a better estimation to perceive the effect of gender on survival rate. MacIntyre and colleagues was detected no association between gender and long term survival (21). Herman and colleagues also stated the excess death occurrence in women is owing to confounders such as, age and treatment modality, in acute myocardial infarction (23). Nonetheless, in our study, a significant better survival was detected for women by taking into account aforementioned potential confounders including, age at diagnosis, diabetes, hypertension, treatment modality, etc. which is in accordance with some other studies $(19,24)$.

It should be noticed that women were more smoker compared to men in the present survey, and in addition to being older, women were more diabetic, which raising the probability that women are more susceptible to have poorer outcome following AMI. Race/ethnicity have been considered for evaluating socioeconomic status $(25,26)$ and higher mortality rate following acute myocardial infarction has been reported for deprived groups (27-29). Our results detected an excess mortality rate in Turkmen and Sistani ethnicity compared to Fars ethnicity. Socioeconomic inequality is an important issue between person (Fars) and nonPersian population in Iran (30) which has been introduced, socioeconomic inequality, as a major factors in AMI (27).
It might be argued that Turkmen and Sistani population, as non- Persian communities, are considered as a deprived group compared to Fars communities. In addition, one study indicated nearly $60 \%$ and $25 \%$ of the Turkmen population were overweight and obesity, respectively, which explain the excess death occurrence of them (31). Our data were detected an excess mortality rate for those who were not prescribed statins, and there were no association between prescription of ACE inhibitor, B blocker, Aspirin, with survival rate which in accordance with the study of Griffith and colleague (2). The advantages of thrombolytic therapy and its safety were detected in some studies $(8,9)$, however; no association was found in the current research with survival rate, which is in line with some national (19) and international studies (2). No significant association between location of myocardial infarction and survival rate, which is accordance with Lenderink and colleague (32) However some studies have shown that mortality rate are different based on myocardial infarction location, as patients are more likely to die with anterior MI $(19,33)$. A survey that conducted by hafshejani and colleague showed the probability of death is 4.2 in subject with anterior MI compared to inferior MI (19).

\section{Conclusion}

A better survival rate for those who were prescribed statin suggest that it could be beneficial in treatment modality and non-Persian ethnicities needed to be considered as a group of at risk for earlier screening programs. In spite of some other studies a poorer outcome was found following AMI for women even after taking into account age and comorbidity.

\section{Acknowledgements}

We thank the students and Golestan University of Medical Science valuable contribution in this research. 


\section{References}

1. Kim AS, Johnston SC. Global variation in the relative burden of stroke and ischemic heart disease. Circulation. 2011;124(3):314-23.

2. Griffith D, Hamilton K, Norrie J, Isles C. Early and late mortality after myocardial infarction in men and women: prospective observational study. Heart. 2005;91(3):305-7.

3. McGovern PG, Jacobs DR, Shahar E, Arnett DK, Folsom AR, Blackburn H, et al. Trends in acute coronary heart disease mortality, morbidity, and medical care from 1985 through 1997 the Minnesota Heart Survey. Circulation. 2001; 104(1):19-24.

4. Tunstall-Pedoe H, Kuulasmaa K, Mahonen M, Tolonen H, Ruokokoski E. Contribution of trends in survival and coronar y-event rates to changes in coronary heart disease mortality: 10year results from 37 WHO MONICA Project populations. Lancet. 1999;353(9164):1547-57.

5. Naghavi M, Abolhassani F, Pourmalek F, Lakeh MM, Jafari N, Vaseghi S, et al. The burden of disease and injury in Iran 2003. Popul Health Metr. 2009;7(1):9.

6. Kubota I, Ito $\mathrm{H}$, Yokoyama $\mathrm{K}$, Yasumura S, Tomoike H. Early mortality after acute myocardial infarction: observational study in Yamagata, 1993-1995. Jpn Circ J. 1998;62(6):414.

7. Davies CA, Leyland AH. Trends and inequalities in short-term acute myocardial infarction case fatality in Scotland, 1988-2004. Popul Health Metr. 2010; 8(33):1-8.

8. Schroder R, Biamino G, Von Leitner ER, Linderer T, Bruggemann T, Heitz $\mathrm{J}$, et al. Intravenous short-term infusion of streptokinase in acute myocardial infarction.

Circulation. 1983;67(3):536-48.

9. Wilcox RG, Olsson CG, Skene AM, Von Der Lippe G, Jensen G, Hampton
JR, et al. Trial of tissue plasminogen activator for mortality reduction in acute myocardial infarction: AngloScandinavian Study of Early Thrombolysis (ASSET). Lancet. 1988;332(8610):525-30.

10. Abildstrom SZ, Rasmussen S, Rosen M, Madsen M. Trends in incidence and case fatality rates of acute myocardial infarction in Denmark and Sweden. Heart. 2003;89(5):507-11.

11. Rosen M, Alfredsson L, Hammar N, Kahan T, Spetz C-L, Ysberg A-S. Attack rate, mortality and case fatality for acute myocardial infarction in Sweden during 1987-95. Results from the national AMI register in Sweden. J Intern Med. 2000;248(2):159-64.

12. Yusuf S, Zucker D, Passamani E, Peduzzi P, Takaro T, Fisher LD, et al. Effect of coronary artery bypass graft surgery on survival: overview of 10year results from randomised trials by the Coronary Artery Bypass Graft Surgery Trialists Collaboration. Lancet. 1994;344(8922):563-70.

13. Yusuf S, Peto R, Lewis J, Collins R, Sleight P. Beta blockade during and after myocardial infarction: an overview of the randomized trials. Prog Cardiovasc Dis. 1985;27(5):33571.

14. Hampton JR. Coronary artery bypass grafting for the reduction of mortality: an analysis of the trials. $\mathrm{Br}$ Med $\mathrm{J}$ (Clinical research ed). 1984;289(6453):1166.

15. Maynard C, Every NR, Martin JS, Kudenchuk PJ, Weaver WD. Association of gender and survival in patients with acute myocardial infarction. Arch Intern Med. 1997;157(12):1379.

16. Tunstall-Pedoe H, World Health O. WHO MONICA project. Geneva: WHO. 2003.

17. Tunstall-Pedoe H, Kuulasmaa K, Amouyel P, Arveiler D, Rajakangas A- 
M, Pajak A. Myocardial infarction and coronary deaths in the World Health Organization MONICA Project. Registration procedures, event rates, and case-fatality rates in 38 populations from 21 countries in four continents.

Circulation. 1994;90(1):583-612.

18. Gottlieb S, Harpaz D, Shotan A, Boyko V, Leor J, Cohen M, et al. Sex Differences in Management and Outcome After Acute Myocardial Infarction in the 1990s A Prospective Observational Community-Based Study. Circulation. 2000;102(20):2484-90.

19. Hafshejani A, Lari M, Hafshejani F. Predicting Factors of Short-term Survival in Patients with Acute Myocardial Infarction in Isfahan Using a Cox Regression Model. Iran J Epid. 2012;8(2)

20. Koek HL, de Bruin A, Gast F, Gevers E, Kardaun JWPF, Reitsma JB, et al. Short-and long-term prognosis after acute myocardial infarction in men versus women. Am J Cardiol. 2006;98(8):993-9.

21. MacIntyre K, Stewart S, Capewell S, Chalmers JWT, Pell JP, Boyd J, et al. Gender and survival: a populationbased study of 201,114 men and women following a first acute myocardial infarction. $\mathrm{J}$ Am Coll Cardiol. 2001;38(3):729-35.

22. Tunstall-Pedoe $\mathrm{H}$, Morrison $\mathrm{C}$, Woodward M, Fitzpatrick B, Watt G. Sex differences in myocardial infarction and coronary deaths in the Scottish MONICA population of Glasgow 1985 to 1991 Presentation, diagnosis, treatment, and 28-day case fatality of 3991 events in men and 1551 events in women. Circulation. 1996;93(11):1981-92.

23. Herman B, Greiser E, Pohiabeln H. A sex difference in short-term survival after initial acute myocardial infarction The MONICA-Bremen Acute
Myocardial Infarction Register, 19851990. Eur Heart J. 1997;18(6):963-70.

24. Kudenchuk PJ, Maynard C, Martin JS, Wirkus M, Weaver WD, Investigators MP. Comparison of presentation, treatment, and outcome of acute myocardial infarction in men versus women (the Myocardial Infarction Triage and Intervention Registry). Am J Cardiol. 1996;78(1):9-14.

25. Anderson RT. Quality of care among disadvantaged women: adding income level to health datasets.WHI. 2003;13(5):177-9.

26. Koh HK, Judge CM, Ferrer B, Gershman ST. Using public health data systems to understand and eliminate cancer disparities. Cancer Causes Control. 2005;16(1):15-26.

27. Machin Mn, Aldasoro E, MartĺnezCamblor P, Calvo M, Basterretxea M, Audicana C, et al. Socioeconomic differences in incidence and relative survival after a first acute myocardial infarction in the Basque Country, Spain. Gaceta Sanitaria. 2012;26(1):16-23.

28. Picciotto S, Forastiere F, Stafoggia M, D'Ippoliti D, Ancona C, Perucci CA. Associations of area based deprivation status and individual educational attainment with incidence, treatment, and prognosis of first coronary event in Rome, Italy. J Epidemiol Community Health. 2006;60(1):37-43.

29. Salomaa V, Niemela M, Miettinen H, Ketonen M, Immonen-Rahina $\mathrm{P}$, Koskinen S, et al. Relationship of socioeconomic status to the incidence and prehospital, 28-day, and 1-year mortality rates of acute coronary events in the FINMONICA myocardial infarction register study. Circulation. 2000;101(16):1913-8.

30. Aghajanian A. Ethnic Ineqality in Iran: An Overview. Int J Middle East Stud. 1983;15(02):211-24.

31. Semnani S, Sadjadi A, Fahimi S, Nouraie M, Naeimi M, Kabir J, et al. Declining incidence of esophageal 
cancer in the Turkmen Plain, eastern part of the Caspian Littoral of Iran: a retrospective cancer surveillance. Cancer Detect Prev. 2006;30(1):14-9.

32. Lenderink T, Hernandez AV, Boersma E, Martinez-Sellés M, Juarez M, Sanchez PL, et al. Prediction of 30-day mortality in older patients with a first acute myocardial infarction. Cardiology. 2009;115(1):1-9.

33. Haim M, Hod H, Reisin L, Kornowski R, Reicher-Reiss H, Goldbourt U, et al. Comparison of short-and long-term prognosis in patients with anterior wall versus inferior or lateral wall non-Qwave acute myocardial infarction. Am J Cardiol. 1997;79(6):717-21. 